\title{
Effect of Metal Acetylacetonates on the Photooxidative Destruction of High Density Polyethylene
}

\author{
Dimitrina Kiryakova ${ }^{a}$, Stiliyana Mihaleva ${ }^{a}$, Atanas Atanassov ${ }^{a}$ \\ ${ }^{a}$ Department of Materials Science, Assen Zlatarov University, Y. Yakimov Str. 1, Burgas 8010, Bulgaria
}

Received: September 1, 2015; Revised: April 20, 2016; Accepted: June 24, 2016

\begin{abstract}
The process of photooxidative destruction of high density polyethylene films containing different organic complexes of polyvalent metals as pro-oxidant additives after UV-irradiation was studied. During exposure to UV- irradiation, the more significant changes in the mechanical and thermal properties were detected for the foils containing pro-oxidant additives compared to initial high density polyethylene. This indicated for the higher degree of oxidation in these samples and confirmed the effectiveness of these additives in promoting the oxidation of high density polyethylene during UV-irradiation. It was found that the decrease of the strength of the initial high density polyethylene foils was more pronounced for the samples with pro-oxidants cobalt (III) acetylacetonate and manganese (II) acetylacetonate. The use of $2 \mathrm{mmol} / \mathrm{kg}$ iron (III) acetylacetonate and $4 \mathrm{mmol} / \mathrm{kg}$ cobalt (III) acetylacetonate as pro-oxidants gave the highest decrease of elongation at break of the polyethylene foils.
\end{abstract}

Keywords: high density polyethylene, pro-oxidants, UV-irradiation, photooxidative degradation, properties

\section{Introduction}

Nowadays, a major part of the polymers with regulated service time are photodestructing polymers. To impart the polymers the ability to destruct under light irradiation, special additives are used or light sensitive groups are introduced in their compositions. Owing to the presence of special groups or compounds in them, they decompose under environment conditions to low molecular weight polymers which are then absorbed by the microorganisms present in soil and air.

Since the synthesis of photodestructing polymers containing carbonyl groups in the chain requires certain changes in the synthesis technology, the efforts of many researchers have been devoted to the use of additives as pro-oxidants in the common polymers. Introduced as various complexes, the salts of polyvalent metals accelerate the interaction of polymers with oxygen from the air ${ }^{1-4}$ by including oxygen atoms in the polyolefin chains.

The attractiveness of these additives is based on their ability to decompose to free radicals under exposure to light, thus generating additional polyethylene macroradicals. They further react with $\mathrm{O}_{2}$ to produce hydroperoxides which are the main reason for the destruction of the polymer ${ }^{5,6}$. The last stage is the self-oxidation and breaking of the PE chain $^{7,8}$ along classic free radical reactions ${ }^{9}$ :

* e-mail: dskiryakova@abv.bg

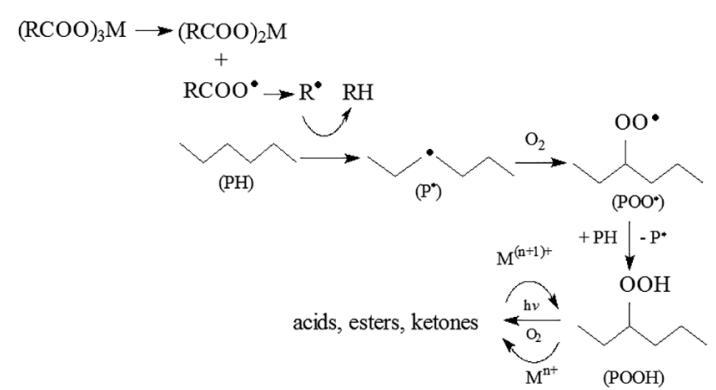

The transition metals possess the unique ability to pass from one oxidation state to another thus catalyzing hydroperoxides destruction ${ }^{10,11}$. They are formed in polymer carcass by the interaction of the polymer with $\mathrm{O}_{2}$ until free radicals are generated through a cycle of redoxy reactions ${ }^{12}$ :

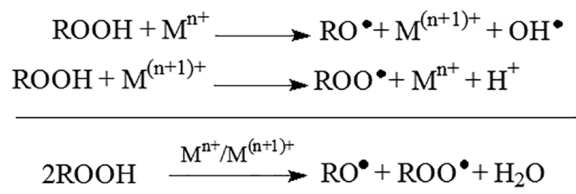

The reactions shown above lead to fast accumulation of hydroperoxides and, simultaneously, to formation of oxidation products with low molecular weight ${ }^{13-16}$.

The aim of the present work is to obtain photodestructing foils on the basis of high density polyethylene by addition of organic complexes of transition metals as pro-oxidants into them. 


\section{Experimental}

\subsection{Materials}

Powdery high density polyethylene (HDPE), product of Lukoil-Neftochim Co., Burgas, Bulgaria, with melting temperature $130^{\circ} \mathrm{C}$, melt index $0.16 \mathrm{~g} / 10$ $\min \left(190^{\circ} \mathrm{C}, 2.160 \mathrm{~kg}\right)$ and density $0.948 \mathrm{~g} / \mathrm{cm}^{3}$ was used for the preparation of the films.

Pro-oxidants: iron acetylacetonate $\mathrm{Fe}(\mathrm{acac})_{3}$ with chemical formula $\mathrm{Fe}\left(\mathrm{C}_{5} \mathrm{H}_{7} \mathrm{O}_{2}\right)_{3}$, melting temperature $180-183^{\circ} \mathrm{C}$, molar weight $353.17 \mathrm{~g} / \mathrm{mol}$ and density $5.24 \mathrm{~g} / \mathrm{cm}^{3}$; cobalt acetylacetonate $\mathrm{Co}(\mathrm{acac})_{3}$, with chemical formula $\mathrm{Co}\left(\mathrm{C}_{5} \mathrm{H}_{7} \mathrm{O}_{2}\right)_{3}$, melting temperature $210-213^{\circ} \mathrm{C}$, molar weight $356.26 \mathrm{~g} / \mathrm{mol}$ and density $1.43 \mathrm{~g} / \mathrm{cm}^{3}$; manganese acetylacetonate $\mathrm{Mn}(\mathrm{acac})_{2}$ with chemical formula $\mathrm{Mn}\left(\mathrm{C}_{5} \mathrm{H}_{7} \mathrm{O}_{2}\right)_{2}$, melting temperature $248-250^{\circ} \mathrm{C}$, molar weight $253.15 \mathrm{~g} / \mathrm{mol}$ and density $1.60 \mathrm{~g} / \mathrm{cm}^{3}$; vanadyl acetylacetonate $\mathrm{VO}(\mathrm{acac})_{2}$ with chemical formula $\mathrm{VO}\left(\mathrm{C}_{5} \mathrm{H}_{7} \mathrm{O}_{2}\right)_{2}$, melting temperature $258^{\circ} \mathrm{C}$, molar weight $265.16 \mathrm{~g} / \mathrm{mol}$ and density 1.50 $\mathrm{g} / \mathrm{cm}^{3}$, all products of Merck, Germany.

\subsection{Sample Preparation}

The compositions containing 2 or $4 \mathrm{mmol} /$ $\mathrm{kg}$ of the pro-oxidants were mixed with HDPE and homogenized in a laboratory mixer (MPW-802, Poland) at $10 \mathrm{~s}^{-1}$ for $15 \mathrm{~min}$. The compositions were formed into pellets (because of their low bulk density) and then pressed in a laboratory press PHI (England) between aluminium foils under the following conditions: samples thickness about $400 \mu \mathrm{m}$, temperature $190^{\circ} \mathrm{C}$, melting period $3 \mathrm{~min}$ at $190^{\circ} \mathrm{C}$, pressing pressure $22 \mathrm{MPa}$ for $1 \mathrm{~min}$ and cooling rate $40^{\circ} \mathrm{C} / \mathrm{min}$.

\subsection{UV-exposition}

The compositions formed as $400 \mu \mathrm{m}$ thick films were irradiated by UV- light with wavelengths in the interval $185-254 \mathrm{~nm}$ emitted by 5 lamps of $8 \mathrm{~W}$ each, at room temperature for $35,60,90,150$, 250 and $300 \mathrm{~h}$.

\subsection{Differential Scanning Calorimeter (DSC) Measurements}

The behavior under melting and crystallization in nitrogen atmosphere of samples with mass ca. $4 \mathrm{mg}$ was analyzed using simultaneous thermal analyzer „STA 449F3 Jupiter” (Netzsch, Germany) under the following conditions: first heating from 20 to $200^{\circ} \mathrm{C}$, followed by cooling to $20^{\circ} \mathrm{C}$ and second heating to $600^{\circ} \mathrm{C}$ at heating rate $12^{\circ} \mathrm{C} / \mathrm{min}$. The degree of crystallinity of the samples was calculated at $\mathrm{DH}_{100 \%}$ $=293 \mathrm{~J} / \mathrm{g}$ for $100 \%$ crystalline $\mathrm{HDPE}^{17}$.

\subsection{Fourier Transform Infrared Spectroscopy (FT-IR)}

Samples prepared as $25-35 \mu \mathrm{m}$ thick films were analyzed using spectrophotometer produced by "Bruker" (Germany) in the interval $4000-400 \mathrm{~cm}^{-1}$ with Tensor 27. To estimate the effect of the addition of pro-oxidants on the degree of degradation of polyethylene, the carbonyl index $(C I)$ of the samples was determined. It is defined as the ratio of absorbance of carbonyl band around $1717 \mathrm{~cm}^{-1}$ and that at 1463 $\mathrm{cm}^{-118}$.

\subsection{Tensile Properties}

The tensile strength, elongation and the other characteristics of the initial HDPE and the foils containing 2 or $4 \mathrm{mmol} / \mathrm{kg}$ of the metal acetylacetonates mentioned above were measured on a dynamometer INSTRON 4203 (England) at speed of $50 \mathrm{~mm} / \mathrm{min}$ and room temperature.

\subsection{Melt Index}

The melt indices of the initial HDPE and the composition based on it, containing $\mathrm{Fe}(\mathrm{acac})_{3}$, were determined by the MFI ( $\mathrm{g} / 10 \mathrm{~min})$ method on an apparatus MFI 3350 Prodemat (France) at temperature of $190^{\circ} \mathrm{C}$ and load $2.160 \mathrm{~kg}$.

\subsection{Sol-gel analysis}

The sol-gel analysis of the initial HDPE and the composition based on it was carried out by extraction with xylene at temperature of $160-170^{\circ} \mathrm{C}$.

\section{Results and Discussion}

The initial temperature of degradation $\left(T_{d}^{i}\right)$, temperatures corresponding to $10 \%\left(\mathrm{~T}_{10}\right), 25 \%\left(T_{25}\right)$ and $50 \%$ mass loss $\left(T_{50}\right)$, maximum rate of decomposition $\left(T_{\mathrm{d}}^{\max }\right)$ and final temperature of decomposition $\left(T_{d}^{f}\right)$ of the materials obtained are presented in Table 1. All the samples studied in inert medium were found to have one stage mechanism of destruction despite the UV light exposure duration, contents and type of the pro-oxidants used. The pyrolysis of the initial irradiated HDPE at heating rate of $12^{\circ} \mathrm{C} / \mathrm{min}$ began at $396.4^{\circ} \mathrm{C}$ and was almost completed at $508.6^{\circ} \mathrm{C}$. Similar tendencies were observed for HDPE by other authors, too ${ }^{19,20}$. The shapes of the $T G$ - curves for the materials containing organic acetylacetonates of iron, cobalt, vanadium and manganese were also similar. In inert medium, the destruction of non-irradiated HDPE begins at $399.7^{\circ} \mathrm{C}$ and is completed at $506.1^{\circ} \mathrm{C}$. For all the irradiated compositions and these containing $\mathrm{Fe}, \mathrm{Co}, \mathrm{Mn}$ and $\mathrm{V}$ acetylacetonates, $T_{d}^{i}$ and $T_{d}^{f}$ were 
Table 1: Temperature characteristics and DSC- thermogram values of the initial, irradiated HDPE and materials based on it with pro-oxidants.

\begin{tabular}{|c|c|c|c|c|c|c|c|c|c|c|c|c|}
\hline \multirow[b]{2}{*}{ Sample } & \multirow{2}{*}{$\begin{array}{c}T_{d}^{i} \\
\left({ }^{\circ} \mathrm{C}\right)\end{array}$} & \multirow{2}{*}{$\begin{array}{c}T_{10} \\
\left({ }^{\circ} \mathrm{C}\right)\end{array}$} & \multirow{2}{*}{$\begin{array}{c}T_{25} \\
\left({ }^{\circ} \mathrm{C}\right)\end{array}$} & \multirow{2}{*}{$\begin{array}{c}T_{50} \\
\left({ }^{\circ} \mathrm{C}\right)\end{array}$} & \multirow{2}{*}{$\begin{array}{l}T_{\mathrm{d}}^{\max } \\
\left({ }^{\circ} \mathrm{C}\right)\end{array}$} & \multirow{2}{*}{$\begin{array}{c}T_{d}^{f} \\
\left({ }^{\circ} \mathrm{C}\right)\end{array}$} & \multicolumn{2}{|c|}{ First melting } & \multicolumn{2}{|c|}{ Second melting } & \multicolumn{2}{|c|}{ Crystallization } \\
\hline & & & & & & & $\begin{array}{c}T_{m} \\
\left({ }^{\circ} \mathrm{C}\right)\end{array}$ & $\alpha(\%)$ & $\begin{array}{c}T_{m} \\
\left({ }^{\circ} \mathrm{C}\right)\end{array}$ & $\alpha(\%)$ & $T_{c}\left({ }^{\circ} \mathrm{C}\right)$ & $\alpha(\%)$ \\
\hline $\begin{array}{l}\text { Non-irradiated } \\
\text { HDPE }\end{array}$ & 399.7 & 448.4 & 465.3 & 478.1 & 478.0 & 506.1 & 128.4 & 66.9 & 128.4 & 66.2 & 111.5 & 66.6 \\
\hline Irradiated HDPE & 396.4 & 454.1 & 466.0 & 478.8 & 480.9 & 508.6 & 128.5 & 72.4 & 127.7 & 70.8 & 112.5 & 67.6 \\
\hline $\begin{array}{l}2 \mathrm{mmol} / \mathrm{kg} \\
\mathrm{Fe}(\mathrm{acac})_{3}\end{array}$ & 400.1 & 452.9 & 465.4 & 478.6 & 480.5 & 507.5 & 128.8 & 71.3 & 127.3 & 70.2 & 112.9 & 68.1 \\
\hline $\begin{array}{l}4 \mathrm{mmol} / \mathrm{kg} \\
\mathrm{Fe}(\mathrm{acac})_{3}\end{array}$ & 406.6 & 465.2 & 478.1 & 486.2 & 483.7 & 508.5 & 128.8 & 73.1 & 127.0 & 71.1 & 112.3 & 68.2 \\
\hline $\begin{array}{l}2 \mathrm{mmol} / \mathrm{kg} \\
\mathrm{Co}(\text { acac })_{3}\end{array}$ & 403.3 & 463.1 & 469.5 & 481.7 & 482.8 & 509.9 & 128.8 & 74.9 & 127.3 & 73.9 & 111.9 & 69.8 \\
\hline $\begin{array}{l}4 \mathrm{mmol} / \mathrm{kg} \\
\mathrm{Co}(\text { acac })_{3}\end{array}$ & 407.5 & 465.4 & 473.6 & 482.3 & 484.9 & 510.9 & 128.6 & 77.1 & 127.4 & 75.1 & 112.2 & 71.9 \\
\hline $\begin{array}{l}2 \mathrm{mmol} / \mathrm{kg} \\
\mathrm{VO}(\text { acac })_{2}\end{array}$ & 400.4 & 460.0 & 472.8 & 483.0 & 484.0 & 508.7 & 129.1 & 69.0 & 128.7 & 72.6 & 112.5 & 65.1 \\
\hline $\begin{array}{l}4 \mathrm{mmol} / \mathrm{kg} \\
\mathrm{VO}(\mathrm{acac})_{2}\end{array}$ & 399.0 & 466.0 & 477.8 & 483.9 & 484.4 & 511.0 & 129.8 & 73.3 & 128.8 & 68.9 & 113.1 & 64.6 \\
\hline $\begin{array}{l}2 \mathrm{mmol} / \mathrm{kg} \\
\mathrm{Mn}(\mathrm{acac})_{2}\end{array}$ & 407.0 & 468.0 & 472.0 & 484.0 & 484.3 & 510.1 & 128.6 & 71.4 & 127.5 & 72.5 & 112.0 & 70.5 \\
\hline $\begin{array}{l}4 \mathrm{mmol} / \mathrm{kg} \\
\mathrm{Mn}(\mathrm{acac})_{2}\end{array}$ & 409.0 & 467.0 & 477.0 & 485.0 & 484.5 & 510.4 & 129.1 & 72.2 & 128.3 & 68.7 & 112.8 & 64.0 \\
\hline
\end{tabular}

almost the same as that of non-irradiated HDPE at the heating rate employed and they were found to be in the range $400.1-409.0$ and $507.5-511.0^{\circ} \mathrm{C}$, respectively. Comparing the temperatures corresponding to 10 , $25,50 \%$ mass loss and $T_{\mathrm{d}}^{\max }$ for the non-irradiated and irradiated HDPE foils with these containing prooxidants, it can be seen that the temperatures increased by $7-20^{\circ} \mathrm{C}$. It can be assumed that during the thermal degradation of samples of high density polyethylene in an inert medium occur two competing processes destruction and recombination. Obtained there from macroradicals probably recombine with each other. Thus, the formed high molecular weight fractions of the polymer require a higher temperature of destruction.

The melting temperatures $T_{\mathrm{m}}$ of the initial non-irradiated and irradiated HDPE, as well as the materials based on it containing $\mathrm{Fe}, \mathrm{Co}, \mathrm{Mn}$ and $\mathrm{V}$ acetylacetonates are shown in the same Table 1. For the initial HDPE, the melting temperature is about $130^{\circ} \mathrm{C}$ and remained unchanged after the addition of pro-oxidants. It means that the UV irradiation had no effect on the $T_{\mathrm{m}}$ of the different samples which is consistent with other publications ${ }^{21,22}$. This is probably related to the predominant attack at the amorphous regions of the samples by UV irradiation.

A tendency of slight increase of the degree of crystallinity $\alpha$ of the samples after first and second melting and crystallization - from 67 to $72 \%$ for the initial and irradiated HDPE. The pro-oxidant containing samples showed behaviors similar to these of the initial irradiated HDPE. The degree of crystallinity of $\mathrm{Co}(\mathrm{acac})_{3}$ containing HDPE compositions was slightly higher - up to $75-77 \%$. The increased crystallinity is probably due to chain scission in polyethylene macromolecules in their amorphous regions as a result from the photooxidation. This allows for formation of shorter fragments which more easily crystalize in the polymer matrix. It is confirmed by other authors ${ }^{23,24}$.

Figure $1 a$ shows the FT-IR spectra of foils from initial and UV irradiated HDPE. The spectrum of the initial polymer has four characteristic bands. The typical bands at 2890 and $2844 \mathrm{~cm}^{-1}$ are attributed to the asymmetric and symmetric valent $-\mathrm{CH}_{2}$ vibrations. The peaks at 1463 and $720 \mathrm{~cm}^{-1}$ are due to the deformation $-\mathrm{CH}_{2}$ vibrations. Because of the high crystallinity of the polymer (about 70\%), the peaks at 1463 and 720 $\mathrm{cm}^{-1}$ are split (doublet) and two additional peaks were observed at 1472 and $730 \mathrm{~cm}^{-125}$. It can be seen that the irradiation of HDPE foils resulted in substantial changes in their spectra ${ }^{26}$. The most significant ones were observed in the carbonyl $\left(1700-1800 \mathrm{~cm}^{-1}\right)$, amorphous $\left(1300 \mathrm{~cm}^{-1}\right)$ and hydroxyl $(3300-3400$ $\mathrm{cm}^{-1}$ ) ranges, as well as that around $909 \mathrm{~cm}^{-1}$ (due to the unsaturated groups).

The addition of pro-oxidants facilitates the initiation and proceeding of radical reactions and processes of macrochain scission. This leads to formation of free radicals which can further interact with air oxygen to oxidize the polymer. For this reason, the oxidizing ability of the acetylacetonates used was studied by 


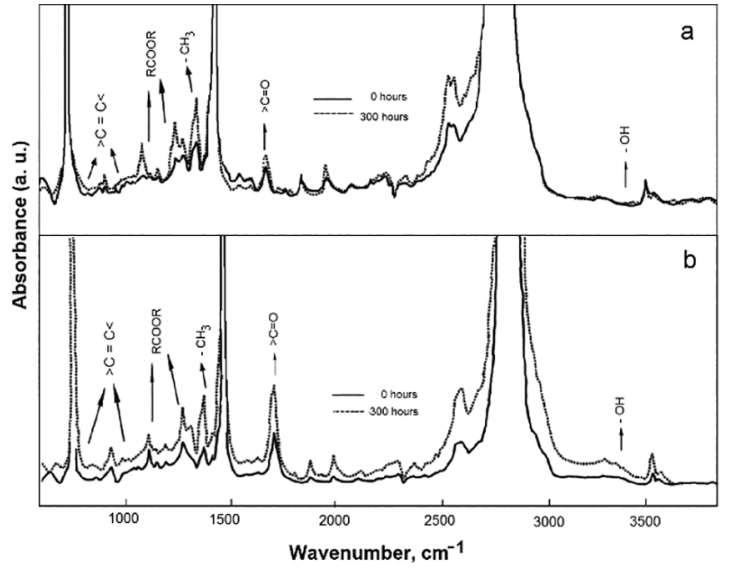

Figure 1: FT-IR spectra of foils of initial non-irradiated (a) and irradiated HDPE containing $2 \mathrm{mmol} / \mathrm{kg}$ polymer pro-oxidant $\mathrm{Co}(\mathrm{acac}) 3$ (b) after exposure 0 and 300 hours

their introduction into HDPE and after irradiation. For both the films of initial irradiated HDPE and the materials based on it containing transition metals acetylacetonates, changes were observed after UV irradiation in all the IR ranges mentioned above. The intensities of these peaks increased as a result from the irradiation (Figure $1 b$ ) which proved the formation of various oxidation products ${ }^{1,12,15}$.

The better photooxidizing ability of pro-oxidant $\mathrm{Mn}(\mathrm{acac})_{2}$ was proved by the carbonyl index determined. The foils containing this pro-oxidant had 10-11 times higher index than that of the initial HDPE after $35 \mathrm{~h}$ irradiation -0.29 (Figure 2). For the materials containing 2 and $4 \mathrm{mmol} / \mathrm{kg}$ polymer $\mathrm{Co}(\mathrm{acac})_{3}$ the carbonyl index increased with the exposure duration with the highest increase being observed with $2 \mathrm{mmol} / \mathrm{kg}$ polymer cobalt (III) acetylacetonate - about 7 times. For the materials containing $4 \mathrm{mmol} / \mathrm{kg}$ polymer pro-oxidant, however, this property didn't change with exposure and remained slightly higher than that of the initial HDPE. The increase of the carbonyl index for the initial HDPE was negligible even after $60 \mathrm{~h} \mathrm{UV-irradiation.} \mathrm{This}$ is due to the fact that the less branched HDPE have limited permeability for gases and smaller number of tertiary carbon atoms in the macromolecule. Therefore stability of HDPE under oxidation is higher than that of LDPE, as it has been reported ${ }^{27}$.

The samples containing $\mathrm{Fe}$ (acac) ${ }_{3}$ showed small increase of the carbonyl index from 0.025 to 0.075 . This was due to reactions of chain scission as a result from the photooxidation which lead to formation of fragments of lower molecular weight ${ }^{28}$. The carbonyl index of the foils with $\mathrm{VO}(\mathrm{acac})_{2}$ was also in the range $0.02-0.07$. The values of this index determined for the $\mathrm{Fe}(\mathrm{acac})_{3}$ and $\mathrm{VO}(\mathrm{acac})_{2}$ foils coincided with these for the initial HDPE despite their concentration in the compositions (Figure 2). This indicates that the use of $\mathrm{Fe}(\mathrm{acac})_{3}$ and $\mathrm{VO}(\mathrm{acac})_{2}$ as pro-oxidants by the photooxidation of the polymer was not effective. It was proved on the basis of the FT-IR analysis that additives of manganese (II) and cobalt (III) acetylacetonates in concentrations $2 \mathrm{mmol} / \mathrm{kg}$ polymer are better be used to obtain higher degree of photooxidation.

The photooxidative destruction is most often studied by properties like strength and elongation at break. This is because the process of destruction is
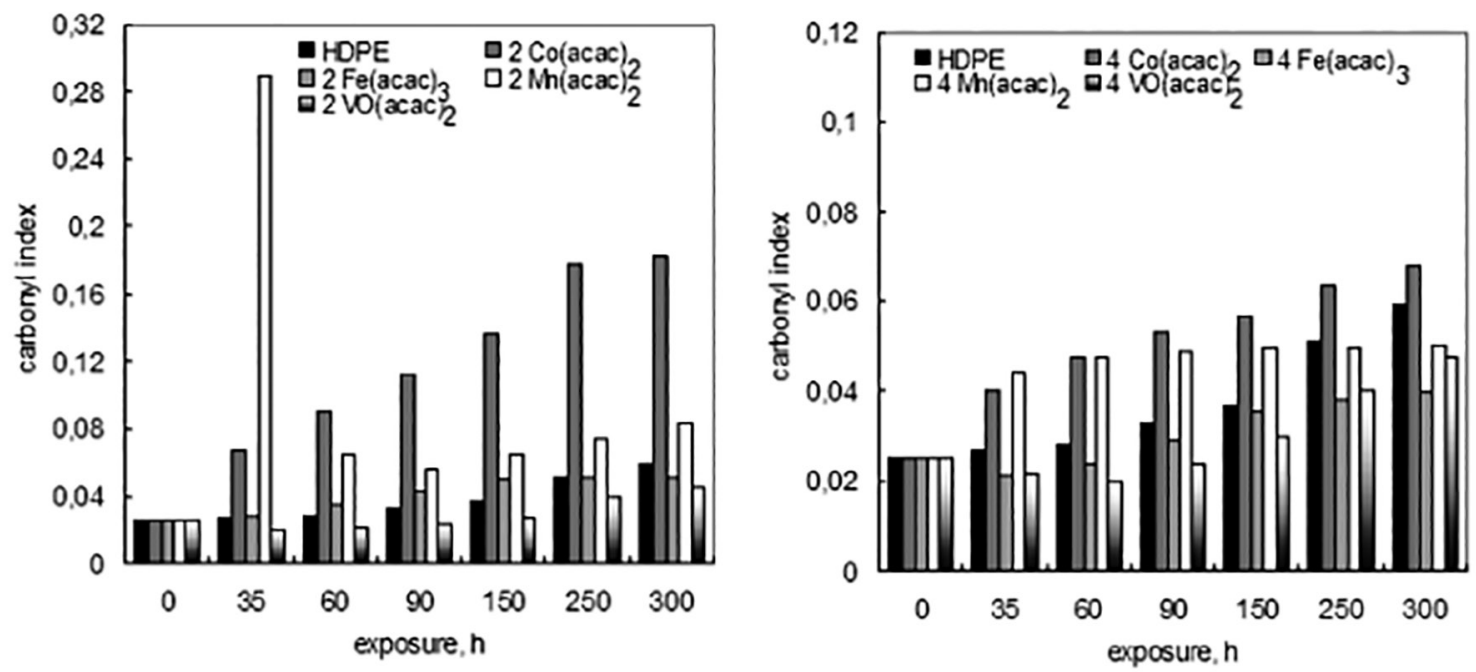

Figure 2: Dependence of the carbonyl index of foils of initial irradiated HDPE and irradiated foils containing pro-oxidants at different exposure times. 
related to deterioration of the mechanical properties. These properties are very sensitive to the destruction and provide information on the degree of oxidation of the polymers ${ }^{27,29}$. The decrease of the strength and especially the elongation at break can be related to the decrease of the polymer molecular weight and formation of defects on samples surface inflicted by the UV irradiation.

The dependencies of the strength at break for initial HDPE and the materials based on it containing 2 and $4 \mathrm{mmol} / \mathrm{kg}$ acetylacetonates on irradiation duration are presented in Figure 3. Obviously, the initial non-irradiated HDPE had strength 21.6 $\mathrm{MPa}$ and it decreased until $60 \mathrm{~h}$ irradiation. After that, the strength increased due to processes of cross-linking taking place in the polymer chains. It was confirmed also by the sol-gel analysis carried out and the melt indices of the initial HDPE and the composites based on it. After the irradiation time mentioned above, the samples contained about $8-12 \%$ gel-fraction and showed melt index in the range $0.07-0.10 \mathrm{~g} / 10 \mathrm{~min}$. The cross-linking of HDPE has been proved by other authors, too ${ }^{30,31}$.

With the addition of acetylacetonates of transition metals the strength at break decreased to higher extent compared to the initial polymer. The only exception were the compositions containing 2 and $4 \mathrm{mmol} / \mathrm{kg}$ polymer $\mathrm{Fe}(\mathrm{acac})_{3}$ for which the strength measured was close or the same as that of the irradiated HDPE. The decrease of the strength of the initial HDPE foils was more pronounced for the samples with pro-oxidants $\mathrm{Co}(\mathrm{acac})_{3}$ and $\mathrm{Mn}(\mathrm{acac})_{2}$ at irradiation durations $35-150 \mathrm{~h}$ (Figure 3). For the $\mathrm{Mn}(\mathrm{acac})_{2}$ containing foils, it decreased as low as
$6-7 \mathrm{MPa}$ after $35 \mathrm{~h}$ irradiation to reach $5 \mathrm{MPa}$ after $60 \mathrm{~h}$ (Figure 3). The polyethylene foils containing 2 and $4 \mathrm{mmol} / \mathrm{kg} \mathrm{VO}(\mathrm{acac})_{2}$ as additive accelerating the process of photooxidation, the strength at break decreased. After $60 \mathrm{~h} \mathrm{UV}$ irradiation it was measured to be about $12 \mathrm{MPa}$ and then gradually increased. The decrease of the strength was due to the decrease of the molecular weight of the polymer matrix - the melt index of the samples was $0.16-0.24 \mathrm{~g} / 10 \mathrm{~min}$ while for the initial HDPE it was $0.16 \mathrm{~g} / 10 \mathrm{~min}$.

Therefore, the use of $\mathrm{Mn}(\mathrm{acac})_{2}$ and $\mathrm{Co}(\mathrm{acac})_{3}$ as pro-oxidants (especially the manganese (II) acetylacetonate in the concentrations mentioned in the Experimental section) exerted stronger effect on the acceleration of the photooxidative destruction processes taking place in HDPE foils.

The change of the elongation at break on irradiation time for all the samples are shown in Figure 4. It can be seen that the initial non-irradiated HDPE had elongation at break $860 \%$. The samples containing $2 \mathrm{mmol} / \mathrm{kg}$ polymer $\mathrm{Fe}(\mathrm{acac})_{3}$ and $4 \mathrm{mmol} / \mathrm{kg} \mathrm{Co}(\mathrm{acac})_{3}$ showed faster decrease of the elongation compared to the initial HDPE. The films containing 2 and $4 \mathrm{mmol} /$ $\mathrm{kg}$ iron (III) acetylacetonate lost $\sim 90 \%$ from their initial elongation after 35 and $60 \mathrm{~h}$, respectively.

The elongation of the foils with $\mathrm{VO}(\mathrm{acac})_{2}$ or $\mathrm{Mn}(\mathrm{acac})_{2}$ also decreased. This tendency is more pronounced for the foils containing $4 \mathrm{mmol} / \mathrm{kg}$ $\mathrm{VO}(\mathrm{acac})_{2}$ after $60 \mathrm{~h}$ irradiation. The initial HDPE films showed only $25 \%$ loss even after $60 \mathrm{~h} \mathrm{UV}$ irradiation and after $90 \mathrm{~h}$ it was about $80-90 \%$. The samples of initial HDPE and these containing salts of transition metals could not be tested after $300 \mathrm{~h}$ irradiation as they became brittle and collapsed.
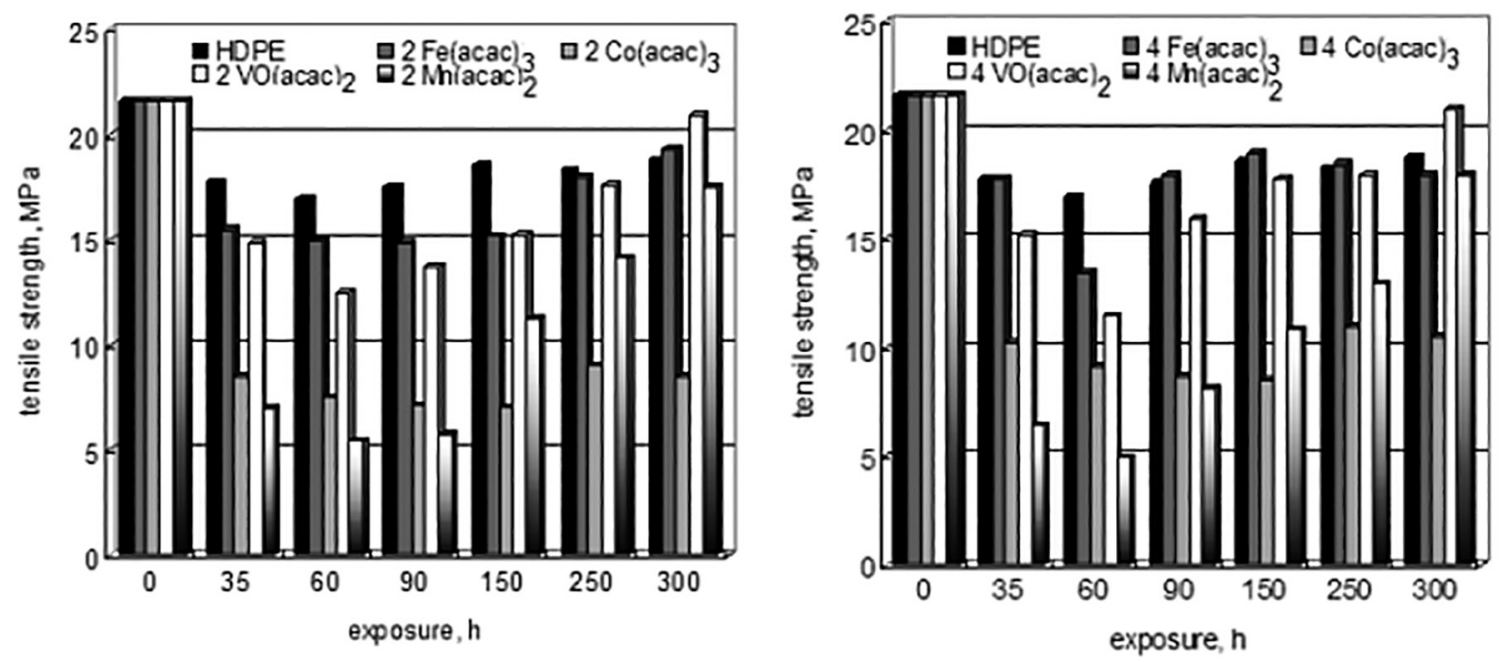

Figure 3: Dependence of the tensile strength of foils of initial irradiated HDPE and irradiated foils containing pro-oxidants at different exposure times 

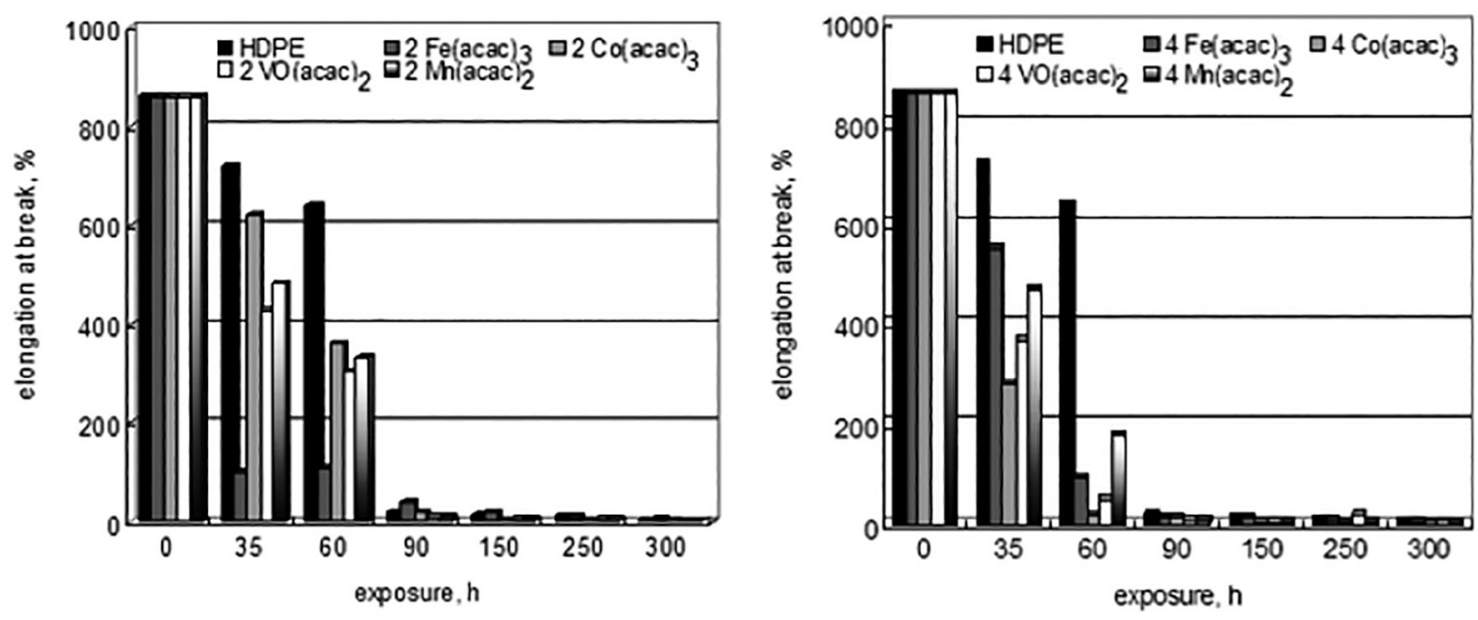

Figure 4: Dependence of the elongation at break of foils of initial irradiated HDPE and irradiated foils containing pro-oxidants at different exposure times.

The highest decrease of the elongation was observed for the HDPE foils containing $2 \mathrm{mmol} / \mathrm{kg}$ iron (III) acetylacetonate and $4 \mathrm{mmol} / \mathrm{kg}$ cobalt (III) acetylacetonate as pro-oxidants. These results correlate well with the data from the FT-IR spectra.

\section{Conclusions}

Photodestructing polymers were obtained on the basis of high density polyethylene and acetylacetonate of iron, cobalt, vanadium and manganese. The chemical and physical changes taking place in the samples with or without pro-oxidants after irradiation from UV source were analyzed. The effect of the acetylacetonates specified on the processes of photodestructive oxidation of the polymer was studied. It was found that by their activity to oxidation the above mentioned pro-oxidants can be arranged in the following order: $\operatorname{Mn}(\text { acac })_{2}>$ $\mathrm{Co}(\mathrm{acac})_{3}>\mathrm{Fe}(\mathrm{acac})_{3} \approx \mathrm{VO}(\mathrm{acac})_{2}$. This shows that the organic complexes used are suitable as additives accelerating the process of photooxidative destruction of high density polyethylene foils.

\section{References}

1. Roy PK, Surekha P, Rajagopal C, Chatterjee SN, Choudhary V. Accelerated aging of LDPE films containing cobalt complexes as prooxidants. Polymer Degradation and Stability. 2006; 91(8): 1791-1799.

2. Sekine Y, Fujimoto K. Catalytic degradation of PP with an Fe/ activated carbon catalyst. Journal of Material Cycles and Waste Management. 2003; 5(2): 107-112.

3. Freitas AR, Vidotii GJ, Rubira AF, Muniz EC. Polychloroprene degradation by a Photo-Fenton process. Polymer Degradation and Stability. 2005; 87(3): 425-432.
4. Roy PK, Surekha P, Rajagopal C, Chatterjee SN, Choudhary V. Effect of benzil and cobalt stearate on the aging of low-density polyethylene films. Polymer Degradation and Stability. 2005; 90(3): 577-585.

5. Corti A, Muniyasamy S, Vitali M, Imam SH, Chiellini E. Oxidation and biodegradation of polyethylene films containing pro-oxidant additives: synergistic effects of sunlight exposure, thermal aging and fungal biodegradation. Polymer Degradation and Stability. 2010; 95(6): 1106-1114.

6. Albertsson AC, Karlsson S. The influence of biotic and abiotic environments on the degradation of polyethylene. Progress in Polymer Science. 1990; 15(2): 177-192.

7. Scott G, Wiles DM. Programmed-Life Plastics from Polyolefins: ANew Look at Sustainability. Biomacromolecules. 2001; 2(3): 615-622.

8. Chiellini E, Corti A, Swift G. Biodegradation of thermally-oxidized, fragmented low-density polyethylenes. Polymer Degradation and Stability. 2003; 81: 341-351.

9. Davis G. Characterization and characteristics of degradable polymer sacks. Mateials Characterization. 2003; 51(2-3): 147-157.

10. Roy PK, Surekha P, Raman R, Rajagopal C. Thermal degradation of star-shaped poly( $\varepsilon$-caprolactone). Polymer Degradation and Stability. 2009; 94(7): 1033-1039.

11. Lemaire J, Gardette JL, Lacoste J, Delprat P, Vaillant D. In: Polymer Durability - Degradation, Stabilization, and Lifetime Prediction, Clough RL, Billingham NC, Gillen KT, Eds., American Chemical Society: Washington DC, Advances in Chemistry Series; 1996. p. 577.

12. Amin MU, Scott G. Photo-initiated oxidation of polyethylene effect of photo-sensitizers. European Polymer Journal. 1974; 10: 1019-1028.

13. Jakubowicz I. Evaluation of degradability of biodegradable polyethylene (PE). Polymer Degradation and Stability. 2003; 80: 39-43.

14. Kyrikou I, Briassoulis D, Hiskakis M, Babou E. Analysis of photo-chemical degradation behaviour of polyethylene mulching film with pro-oxidants. Polymer Degradation and Stability. 2011; 96: 2237-2252.

15. Suresh B, Maruthamuthu S, Khare A, Palanisamy N, Muralidharan VS, Ragunathan R, Kannan M, Pandiyaraj KN. Influence of thermal oxidation on surface and thermo-mechanical properties of polyethylene. Journal of Polymer Research. 2011; 18(6): 2175-2184. 
16. Ojeda T, Freitas A, Birck K, Dalmolin E, Jacques R, Bento F, Camargo F. Degradability of linear polyolefins under natural weathering. Polymer Degradation and Stability. 2011;96: 703-707.

17. Mark EJ. Physical properties of polymers handbook Springer: New York; 2007.

18. Ohtake Y, Kobayashi T, Asabe H, Murakami N. Biodegradation of low-density polyethylene, polystyrene, polyvinyl chloride, and urea formaldehyde resin buried under soil for over 32 years. Journal of Applied Polymer Science. 1995; 56: 1789-1796.

19. Kayacan I, Dogan OM. Pyrolysis of Low and High Density Polyethylene. Part I: Non-isothermal Pyrolysis Kinetics. Energy Sources, Part A. 2008; 30(5): 385-391.

20. Encinar JM, Gonzalez JF. Pyrolysis of Synthetic Polymers and Plastic Wastes. Kinetic Study. Fuel Processing Technology. 2008; 89(7): 678-686.

21. Valadez-Gonzalez A, Cervantes-Uc JM, Veleva L. Mineral filler influence on the photo-oxidation of high density polyethylene: I. Accelerated UV chamber exposure test. Polymer Degradation and Stability. 1999; 63(2): 253-260.

22. Chrissafis K, Paraskevopoulos KM, Pavlidou E, Bikiaris D. Thermal degradation mechanism of HDPE nanocomposites containing fumed silica nanoparticle. Thermochimica Acta. 2009; 485(1-2): 65-71.

23. Grigoriadou I, Paraskevopoulos KM, Chrissafis K, Pavlidou E, Stamkopoulos TG, Bikiaris D. Effect of different nanoparticles on HDPE UV stability. Polymer Degradation and Stability. 2011; 96(1): 151-163.
24. Morlat-Therias S, Mailhot B, Gonzalez D, Gardette JL. Photooxidation of Polypropylene/Montmorillonite Nanocomposites. 2. Interactions with Antioxidants. Chemistry of Materals. 2005; 17(5), 1072-1078.

25. Gulmine JV, Janissek PR, Heise HM, Akcelrud L. Polyethylene characterization by FTIR. Polymer Testing. 2002; 21(5): 557-563.

26. Fabiyi JS, McDonald AG, Wolcott MP, Griffiths PR. Wood plastic composites weathering: Visual appearance and chemical changes. Polymer Degradation and Stability. 2008; 93(8): 1405-1414.

27. Barr-Kumarakuiasinghe SA. Modelling the thermal oxidative degradation kinetics of polyethylene film containing metal pro-oxidants. Polymer. 1994; 35(5): 995-1003.

28. Kulich DM, Wolkowicz MD. In: Rubber-Toughened Plastics, Riew CK, Ed., American Chemical Society: Washington DC; 1989. p. 329.

29. Andrady AL, Pegram JE, Nakatsuka S. Studies on enhanced degradable plastics: 1 . The geographic variability in outdoor lifetimes of enhanced photodegradable polyethylenes. Journal of Polymers and the Environment. 1993; 1(1): 31-43.

30. Torikai A, Asada S, Fueki K. Photodegradation of crosslinked polyethylene. Polymer Photochemistry. 1986; 7(1):1-11.

31. Torikai A, Takeuchi A, Nagaya S, Fueki K. Photodegradation of polyethylene: Effect of crosslinking on the oxygenated products and mechanical properties. Polymer Photochemistry. 1986; 7(3): 199-211. 